\title{
Commentary on 'Private Sector Metrics Contributions to Social Change: Customer Satisfaction Meets Agriculture Development'
}

\author{
Edward Mabaya
}

\begin{abstract}
David Bonbright and Jamey Powers' IDS Bulletin article entitled 'Private Sector Metrics Contributions to Social Change: Customer Satisfaction meets Agriculture Development' proposes a refreshingly simple and yet profound approach to an age-old challenge. The authors suggest the application of customer satisfaction survey methods to agricultural development projects wherein the smallholder farmer is given a voice in project design, implementation and accountability. In keeping with the simple and yet elegant style of the article, this comment addresses the following three questions: (1) What is the main contribution of the article? (2) What else can agriculture development practitioners learn from private sector customer satisfaction? (3) What are the potential pitfalls of this approach?'
\end{abstract}

David Bonbright and Jamey Powers' article in this IDS Bulletin entitled 'Private Sector Metrics Contributions to Social Change: Customer Satisfaction meets Agriculture Development' proposes a refreshingly simple and yet profound approach to an age-old challenge. The authors suggest the application of customer satisfaction survey methods to agricultural development projects wherein the smallholder farmer is given a voice in project design, implementation and accountability. Now that is an idea that makes you think 'Why didn't someone think of that before?' In keeping with the simple and yet elegant style of the article, this comment addresses the following three questions:

(1) What is the main contribution of the article?

(2) What else can agriculture development practitioners learn from private sector customer satisfaction? (3) What are the potential limitations and pitfalls of this approach?

As noted in the article, for the last six decades the private sector has excelled in every corner of the world providing numerous products and services to billions of satisfied customers. During the same period, agricultural development practitioners have attempted, with very little success, to improve rural livelihoods in sub-Saharan Africa and South Asia. Despite massive investments in increasing usage and quality of seed, fertiliser, extension services and market access, agricultural productivity has remained stagnant. It is against this background that Bonbright and Powers' article contributes to a growing body of literature on strategies to improve development work using approaches that have been tried and tested in the private sector arena. Specifically, the article proposes a paradigm shift from the traditional supply-driven agriculture development management practices that seek to introduce something exogenous to improve agricultural productivity to demanddriven approaches that put the smallholder farmers first. Given the increasing emphasis by donors on better and visible results, coupled with a precipitous decline in the cost of gathering information from smallholder farmers (resulting from advances in information and communication technologies), the authors rightly identify a unique window to cultivate farmer voice in agricultural development. If the philosophy, strategies, and frameworks of 'consumer satisfaction' can be incorporated into agricultural development, it could positively

IDS Bulletin Volume 41 Number 6 November 2010 C 2010 The Author. Journal compilation (c) Institute of Development Studies Published by Blackwell Publishing Ltd, 9600 Garsington Road, Oxford OX4 2DQ, UK and 350 Main Street, Malden, MA 02148, USA 
transform this sector like it has numerous industries since the 1960s. Using a hypothetical coffee project in East Africa, the article illustrates how farmer feedback systems can be incorporated in project design and implementation to improve efficacy.

One of the key benefits of adapting business craft to development work is not having to reinvent the wheel. We can take advantage of the best practices while forgoing the costly lessons that the pioneering companies had to learn. The authors already outline some key lessons on customer satisfaction surveys to see how these relate to the world of agricultural development. However, a few additional lessons are worth noting. First, the quality of information is dependent on primary data collection methods. The intricacies of how, when, and how often to gather information from customers should not be taken lightly given the numerous pitfalls in the methods. For this reason, many private companies utilise the services of specialised market research firms to collect, analyse and strategise on customer feedback systems. Wrong techniques will yield bad data, wrong information, poor strategies, and consequently failure to achieve desired goals. The development community should be forewarned to invest the requisite time and resources into developing appropriate systems for customer feedback or else outsource the job to experienced experts in the private sector. Second, participation of the customers is neither mandatory nor guaranteed. After the first wave of euphoria about finally having a say has worn off, farmer participation in customer satisfaction surveys is likely to decline as it does in every sector. Increasingly, only those farmers who feel strongly that they have something important to say will participate, leading to a self-selection bias. To encourage broad participation by all constituencies or stakeholders, incentives might have to be built into the projects while balancing objectivity and guaranteeing anonymity when needed. Third and perhaps most importantly, customer satisfaction surveys are only as useful as they are utilised. From an agricultural development perspective, the measure of success should be less about 'giving a voice to the farmers' and more about 'listening and implementing the farmers' voice.' The latter is likely to be a bigger hurdle to jump given the nearly a century of top-down supply-driven approaches to agricultural development. Related to this point, it is worth noting that once farmer feedback loops are established, the credibility of the project will likely suffer unless issues raised by farmers are promptly and adequately addressed.

As tempting as it is to borrow from successful models developed in the private business arena and map them onto the agricultural development world, one should remember to acknowledge the significant differences between the two worlds. Bonbright and Powers do caution against such copying. Chief among the important differences is the fact that farmers in agricultural development projects, unlike regular customers, do not face a budget constraint. Without a good sense of the costs, wellintentioned farmer feedback loops can yield nothing more than elaborate wish lists and possibly an entitlement mentality. To mitigate against this potential hazard, farmers will need to be educated first on the scope of what is feasible under budget constraints and where the trade-offs lie. Lastly, we must acknowledge the expertise of programme officers and project administrators. Unlike farmers, they often have the added benefit of having studied and/or witnessed numerous case studies from which key lessons can be learnt (much like product development managers responding to customer satisfaction surveys). The solution therefore lies neither with the farmers nor with agricultural development professionals, but rather in finding the balance between the voices of the former and the expertise of the latter. 